\title{
Test-Retest Reliability of Multiple Sleep Latency Test in Diagnosis of Narcolepsy
}

\author{
Min Jae Seong ${ }^{1}$, Su Jung Choi ${ }^{2,3}$, Seung Bong Hong ${ }^{2}$, Eun Yeon Joo $^{2}$ \\ ${ }^{1}$ Department of Neurology, Myongji Hospital, Goyang, \\ ${ }^{2}$ Department of Neurology, Neuroscience Center, Samsung Medical Center, Sungkyunkwan University School of Medicine, Seoul, \\ ${ }^{3}$ Department of Nursing, Department of Clinical Nursing Science, Samsung Medical Center, Sungkyunkwan University School of Medicine, \\ Seoul, Korea
}

\author{
기면병 환자에서 다중수면잠복기검사의 검사-재검사 신뢰도 검증 \\ 성민재 ${ }^{1}$, 최수정 ${ }^{2.3}$, 홍승봉 ${ }^{2}$, 주은연 ${ }^{2}$ \\ 명지병원 신경과, ${ }^{1}$ 성균관대학교 의과대학 삼성서울병원 신경과, 뇌신경센터, ${ }^{2}$ 삼성서울병원 간호부, 성균관대학교 임상간호대학원 ${ }^{3}$
}

Received November 12, 2020

Revised December 10, 2020

Accepted December 10, 2020

Address for correspondence

Eun Yeon Joo, MD, PhD

Department of Neurology,

Neuroscience Center,

Samsung Medical Center,

Sungkyunkwan University

School of Medicine, 81 Irwon-ro,

Gangnam-gu, Seoul 06351, Korea

Tel: +82-2-3410-3597

Fax: +82-2-3410-0052

E-mail: eunyeon.joo@gmail.com

Objectives: The diagnosis of hypersomnia may be changed by the repeated multiple sleep latency test (MSLT). We investigated the long-term reliability of MSLT in the diagnosis of narcolepsy type 1(NT1) and 2 (NT2). Methods: We reviewed the data of patients with NT1 and NT2 who underwent MSLT at least twice between 2008 and 2020. The clinical information and polysomnography/MSLT data were thoroughly assessed, and two sleep experts evaluated the consistency and reliability of diagnosis independently. Results: Eighty patients ( 38 with NT1 and 42 with NT2 as a final diagnosis) were included in this study. Of the 80 patients, 20 (nine with NT1 and 11 with NT2) underwent the 3rd MSLT. No significant differences were found in the sleep data and Epworth Sleepiness Scale at baseline. During the 2nd MSLT, 18.4\% ( $n=7)$ patients with NT1 and $47.6 \%(\mathrm{n}=20)$ patients with NT2 did not satisfy the diagnosis of narcolepsy. At the 3rd MSLT, six out of nine patients with NT1 and seven of 11 patients with NT2 were not suitable for narcolepsy. Two of the initial NT1 (5.2\%) and 10 of the initial NT2 (23.8\%) patients were found to be normal. Three patients who were confirmed to have NT1 through consecutive MSLTs had significantly shorter sleep latency and more number of sleep-onset rapid eye movements than the other patients. Conclusions: The reliability of MSLT were not robust in the diagnosis of NT1 and NT2 in this long-term follow-up study. The MSLT results should be interpreted with careful consideration based on elaborate preparations.

J Sleep Med 2020;17(2):175-180

Key Words: Narcolepsy, Multiple sleep latency test, Test-retest reliability.

\section{서 론}

중추성과다수면장애(central disorders of hypersomnolence)는 1형 기면병(narcolepsy type 1, NT1), 2형 기면병 (narcolepsy type 2, NT2), 그리고 특발성 수면과다증(idiopathic hypersomnia, $\mathrm{IH}$ )이 포함된 수면질환이다..$^{1-3}$ 뇌척수 액 내 히포크레틴-1의 결핍은 기면병 진단에 결정적으로 중

This is an Open Access article distributed under the terms of the Creative Commons Attribution Non-Commercial License (https://creativecommons.org/licenses/by-nc/4.0) which permits unrestricted non-commercial use, distribution, and reproduction in any medium, provided the original work is properly cited.
요하지만, ${ }^{45}$ 국내에서 히포크레틴 검사가 어렵다. 또한 HLA $\mathrm{DQB} 1 * 0602$ 검사 비용이 비싸서 폭넓게 시행하지 못하고 있 다. 이에 아직 국내에서는 기면병의 진단을 임상소견과 다중 수면잠복기검사(multiple sleep latency test, MSLT) 결과에 의존하는 실정이다. ${ }^{6}$ 기면병으로 진단하기 위해서는 MSLT 에서 평균 수면 잠복기가 8 분 이하이고, 2 회 이상의 수면개시 REM수면(sleep-onset REM, SOREM)이 출현해야 한다.7.8 공교롭게도 이 MSLT 지표들은 항우울제나 항경련제와 같 은 약물, 교대근무, 만성수면부족, 일주기리듬수면각성장애, 수면호흡장애와 같은 다양한 수면질환 및 환경에 영향을 받 
을 수 있다. ${ }^{7}$ MSLT 전날 수면다원검사를 시행하여 수면호흡 장애는 배제할 수 있으나, 약물복용이나 일주기리듬수면각 성장애 및 만성수면부족은 1 회의 수면다원검사로 확인하기 어렵다. 야간수면 뿐만 아니라, 주간수면 측정에 대한 변동 성이 큰 만큼 MSLT를 반복 시행하여 보다 더 정확한 진단 을 하고자 하는 연구가 많았다. 본 연구진은 지난 2008년 과 도한 주간졸음을 호소하나 첫 번째 MSLT에서 중추성과다 수면장애에 합당한 소견이 나오지 않았던 27명을 대상으로 $1 \sim 3$ 개월 후 두 번째 MSLT를 시행하였을 때, 33\%는 기면 병, 59.2\%는 IH로 진단하여 반복적인 MSLT의 유용성을 보 고한 바 있다. ${ }^{9}$ 다른 연구에서, NT1의 $81 \%$ 는 두 번째 MSLT 에서도 진단이 일치했으나 NT2와 $\mathrm{IH}$ 는 각각 $18 \%, 47.1 \%$ 의 일치율을 보여서 중추성과다수면장애를 1 회의 MSLT 결과 로 진단하는 것에 대한 우려가 제기되었다. ${ }^{10-12} \mathrm{MSLT}$ 검사재검사의 낮은 신뢰성은 중추성과다수면장애의 임상경과에 따라 질병의 심각도와 예후가 달라질 수 있음을 시사한다. 본 연구에서는 첫 번째 MSLT에서는 NT1 또는 NT2로 진단 되었으나 추적 MSLT를 통하여 진단이 변경된 경우를 확인 해보고자 했고, 2회 또는 3회 MSLT를 시행한 경우를 분석하 여 재검사 횟수에 따른 검사 결과의 변동성, 진단이 변경된 환자와 유지된 환자의 임상 특성의 차이점을 밝히고자 한다.

\section{방 법}

\section{연구 대상}

2008 2020년 사이 동안 과도한 주간졸음(excessive daytime sleepiness)으로 내원한 환자들 중 MSLT를 2회 이상 시행한 134명에 대해 후향적으로 의무기록을 조사하였다. MSLT 결과에 영향을 줄 것이 분명하게 명기된 수면호흡장 애(sleep-related breathing disorders), 교대근무병(shift work disorder), 일주기리듬수면-각성장애(circadian rhythm sleepwake disorder), 수면관련운동장애(sleep-related movement disorders)가 동반된 54명을 제외했다. 임상정보 및 수면검사 를 통해 NT1 또는 NT2로 진단된 80명 중 MSLT를 2회 진행 한 군과 3 회 진행한 군으로 분류하여 성별, 검사 당시 연령, 검사 간격, 약물복용력, Epworth Sleepiness Scale(ESS) 및 수면검사 결과를 분석했다(Fig. 1). NT1과 NT2 진단은 International Classification of Sleep Disorders-Third Edition (ICSD-3) 기준에 근거했으며 뇌척수액 히포크레틴 검출은 시행할 수 없었기에 뚜렷한 탈력발작이 동반되거나 병력이 있는 경우를 NT1으로 진단하였다. ${ }^{1}$

본 연구에 사용된 연구 기준, 방법 및 평가는 삼성서울병원 기관윤리심의위원회의 심의(승인번호 2020-03-206)와 동의 면제 승인을 획득하였으며, 기관윤리심의위원회의 관리감독

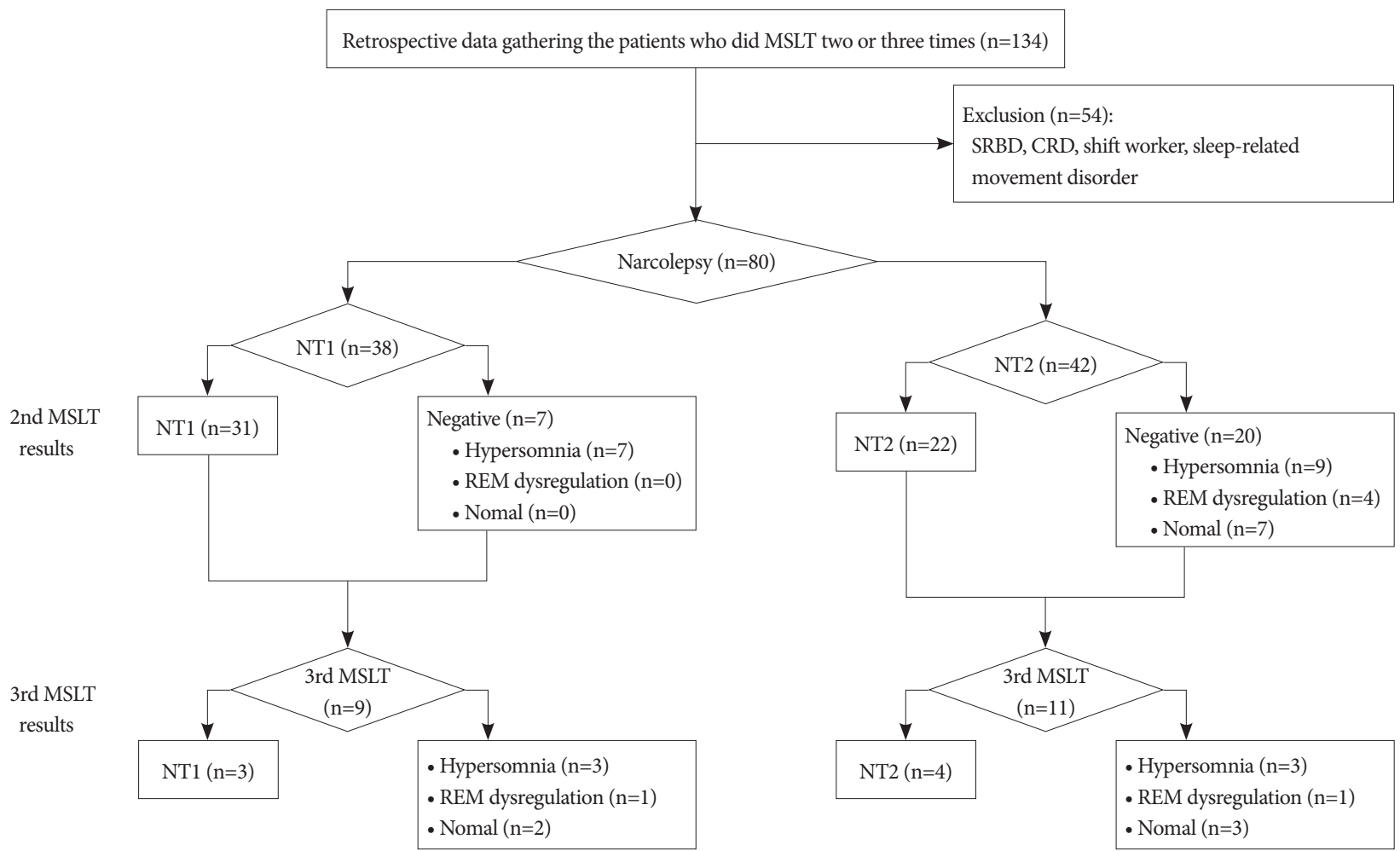

Figure 1. Represents the flow of diagnostic changes in patients with NT1 and NT2. MSLT: multiple sleep latency test, NT1: narcolepsy type 1, NT2: narcolepsy type 2, SRBD: sleep related breathing disorder, CRD: circadian rhythm disorder. 
하에 시행되었다.

\section{검사 항목}

야간 수면다원검사(overnight polysomnography)는 Embla N7000(Medcare Flaga, Reykjavik, Iceland)를 사용하였 다. 뇌파(C3-A2, C4-A1, F3-A2, F4-A1, O1-A2, O2-A1), 4채널 안전위도(electro-oculography) 및 턱 근전도로 수면 단계와 각성을 판정하였으며 흥곽과 복부벨트를 이용하여 호흡운동을 측정하였다. 호흡량은 온도감지센서와 압력센서 로 측정하였으며 심전도, 양측 전경골근(anterior tibialis)에 부착한 2채널의 근전도, 맥박산소측정(pulse oximetry)을 측 정하였다. 수면다원검사의 판독은 미국수면학회(American Academy of Sleep Medicine)의 지침에 근거하였다. ${ }^{13}$

환자들은 수면검사 2 주 전부터 검사결과에 영향을 미칠 수 있는 약물(modafinil, armodafinil, methylphenidate 및 selective serotonin-norepinephrine reuptake inhibitors, selective serotonin reuptake inhibitors, tricyclic antidepressants, hypnotics)을 중단하도록 교육했다. 또한, 2015년 부터는 같은 기간 수면일기를 기록하게 하여 정상적인 수 면-각성주기를 유지하는지, 최소한 6시간 이상의 야간 수면 을 취하는지 확인했다. ${ }^{1}$ MSLT는 야간수면검사를 시행한 다 음날 아침 기상 2시간 후부터 시작하였으며 2시간 간격으로 분리된 5회의 낮잠으로 구성되었다. 수면잠복기(sleep latency)는 불을 끈 시간부터 환자가 잠들기 시작한 첫 번째 에 포크(epoch)까지의 시간으로 정의하였고, 평균수면잠복기 (mean sleep latency)는 5회의 낮잠에서 수면잠복기 평균을 계산하여 나온 값으로 확인하였다. SOREM은 잠들기 시작 한 후 15 분 이내에 나타나는 렘 수면으로 정의하였다.

MSLT 결과에 따라 다음과 같이 진단했다. ${ }^{1} 1$ ) 평균수면잠 복기 $\leq 8$ 분, 그리고 $2 \geq \mathrm{SOREM}$ : 기면병형 (narcolepsy phenotype), 2) 평균수면잠복기 $\leq 8$ 분, 그리고 <2 SOREM: 과 수면형(hypersomnia phenotype), 3) 평균수면잠복기 $>8$ 분, 그리고 $2 \geq S O R E M$ : 렘 조절 장애형(REM dysregulation), 4) 평균수면잠복기>8분, 그리고 <2 SOREM: 정상(normal phenotype)

분석 항목은 다음과 같다.

1) 기면병 유형(NT1 vs. NT2)에 따른 임상양상 및 수면검 사 비교

2) MSLT 반복검사 및 추적관찰 기간에 따라 변경된 진단 의 종류 및 특성

\section{통계 방법}

통계 분석은 SPSS 18.0(SPSS Inc., Chicago, IL, USA)을
이용하였다. 범주형 변수는 chi-square test 또는 Fisher's exact test를 시행하였으며 연속형 변수에 대해서는 independent T-test 또는 Mann-Whitney U test로 분석하였다. 모든 분석은 $p<0.05$ 인 경우 유의한 것으로 판단하였다.

\section{결 과}

\section{기면병 유형과 MSLT 검사 횟수에 따른 임상양상 및 수면검사 비교(Table 1)}

첫 번째 MSLT에서 38명은 NT1으로, 42명은 NT2로 확인 되었다. MSLT의 첫 번째와 두 번째 검사 간격은 각각 $4.0 \pm$ 2.5년(NT1), 3.7 \pm 2.9 년(NT2)로 차이가 없었다 $(\mathrm{p}=0.56)$. 첫 진단 당시 두 군 간의 인구학적 특성은 차이가 없었다.

첫 번째 MSLT에서 NT1의 평균수면잠복기는 3.0 2.8 분, $\mathrm{NT} 2$ 는 $4.4 \pm 3.6$ 분이며 통계적 차이는 없었다 $(p=0.06)$. 수면 다원검사 지표와 $\mathrm{ESS}$ 차이도 없었다.

3 회 검사를 시행한 환자는 NT1이 9명, NT2가 11명이었 다. 인구학적 특성에서 차이를 보이지 않았고 첫 진단 검사 연령 및 총 경과관찰 기간에서도 차이가 없었다. MSLT에서 $\mathrm{NT} 1$ 의 렘수면잠복기가 더 짧았으나 통계적 차이는 없었다 (2.3 \pm 3.0 분 vs. $4.8 \pm 2.2$ 분, $p=0.08)$. 수면다원검사 지표와 $\mathrm{ESS}$ 차이도 없었다.

2015년 이후 시행한 MSLT에서는 2주간 수면일기 또는 액 티그라피로 충분한 수면시간 유지 여부를 확인하였다. 2014년 이전에 반복 MSLT 검사를 모두 시행한 환자는 총 17 명이었 으며 NT1이 8명, NT2가 9명이었다. 2015년 이후 MSLT를 시행한 환자는 NT1이 30명, NT2가 33명이었으며, 기면병 유 형의 분포는 차이를 보이지 않았다 $(p=0.96)$. 또한 2015년 전, 후를 비교 하였을 때 MSLT 및 수면다원검사에서 유의한 차 이를 보이는 지표는 없었다.

\section{MSLT 반복검사 및 경과관찰 기간에 따라 변경된 진단의 종류 및 특성(Table 2)}

추적 MSLT에 근거한 진단의 변경을 보면, MSLT를 2회만 시행한 환자는 NT1이 29명, NT2가 31명이었다. 그 중에서 두 번째 검사에서 NT1은 7명(24.1\%), NT2는 20명(64.5\%)에서 기존 진단과 달랐다. NT1에서는 7명(100.0\%)이 과수면형으로 판명되었다. NT2에서는 9명(45.0\%)이 과수면형, 4명(20.0\%) 이 렘 조절 장애형, 7 명(35.0\%)은 정상으로 판명되었다.

3 회 검사를 시행한 환자만으로 분석하였을 때, 첫 검사에서 NT1으로 진단되었으나, 세 번째에서 진단이 변경된 경우는 총 6명으로, 3명(50.0\%)은 과수면형, 1명(16.6\%)은 렘 조절 장 애형, 2명(33.4\%)은 정상으로 밝혀졌다. 첫 검사에서 NT2로 
Table 1. Polysomnography, MSLT and clinical characteristics according to the number of MSLT in NT1 and NT2

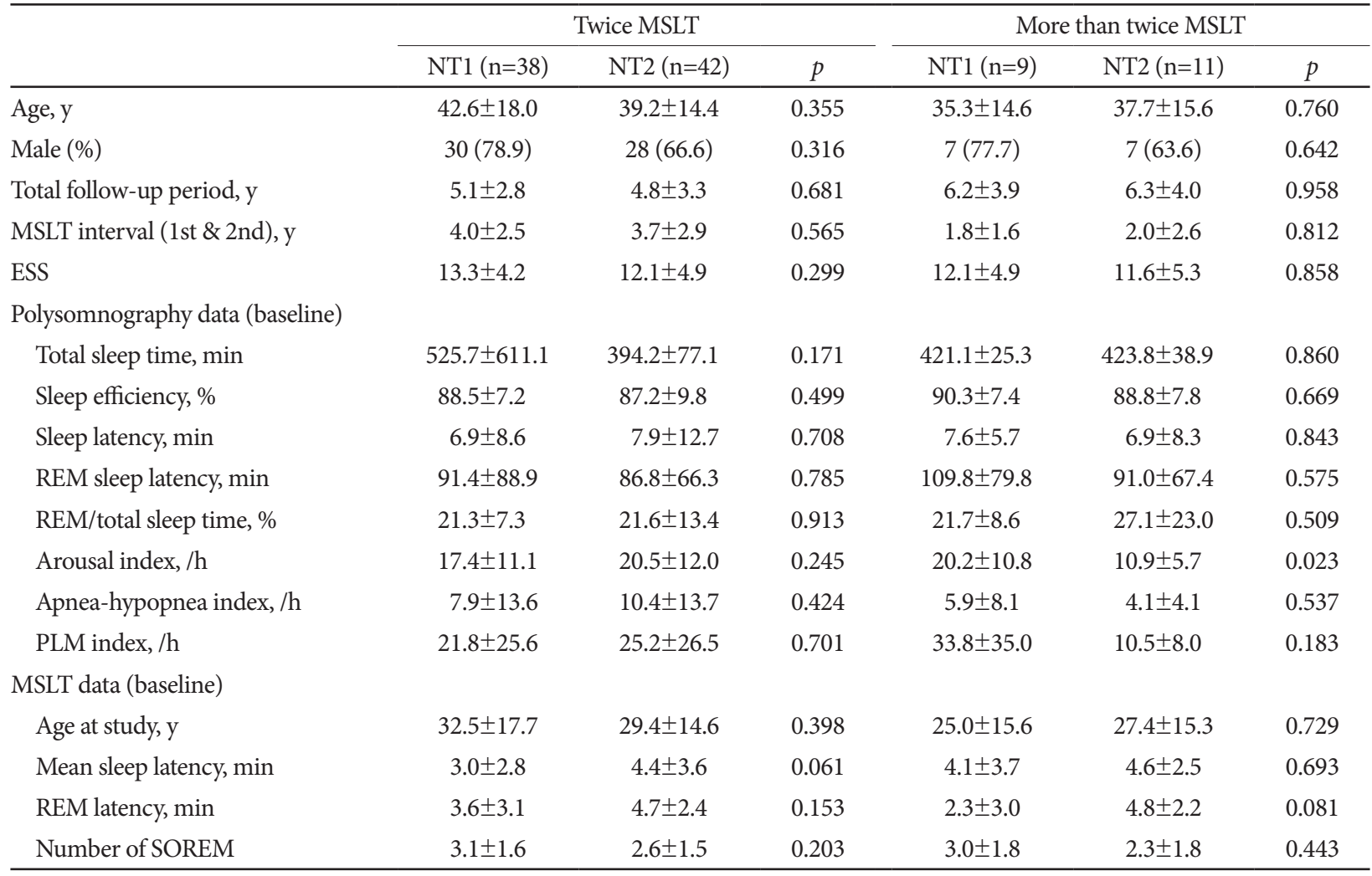

MSLT: multiple sleep latency test, SOREM: sleep-onset REM, NT1: narcolepsy type 1, NT2: narcolepsy type 2, ESS: Epworth Sleepiness Scale, PLM: periodic limb movement

Table 2. Characteristics of diagnosis change in NT1 and NT2 according to number of tests

\begin{tabular}{|c|c|c|c|c|c|c|}
\hline & \multicolumn{3}{|c|}{ MSLT twice } & \multicolumn{3}{|c|}{ More than twice MSLT } \\
\hline & NT1 (n=29) & NT2 $(n=31)$ & $p$ & NT1 (n=9) & NT2 $(n=11)$ & $p$ \\
\hline \multicolumn{7}{|l|}{ Diagnosis change according to ICSD-3 } \\
\hline Hypersomnia & 7 & 9 & 0.002 & 3 & 3 & 0.881 \\
\hline REM dysregulation & 0 & 4 & & 1 & 1 & \\
\hline Normal & 0 & 7 & & 2 & 3 & \\
\hline Total (\%) & $7(24.1)$ & $20(64.5)$ & & $6(66.6)$ & $7(63.6)$ & \\
\hline Interval between 2nd and 3rd MSLT, y & & & & $2.4 \pm 1.7$ & $2.1 \pm 2.1$ & 0.749 \\
\hline
\end{tabular}

MSLT: multiple sleep latency test, ICSD-3: International Classification of Sleep Disorders-Third Edition, NT1: narcolepsy type 1, NT2: narcolepsy type 2

진단되었으나, 세 번째에서 다른 질환으로 변경된 경우는 총 7명이었다: 과수면형 3명(42.9\%), 렘 조절 장애형 1명(14.2\%). 정상 3 명 $(42.9 \%)$.

반복검사에서 연속 NT1으로 확인된 환자들 $(n=25)$ 은, 반 복검사에서 1 회 이상 $\mathrm{NT} 1$ 이 아닌 것으로 나온 환자들 $(\mathrm{n}=13)$ 에 비해 주관적 졸림 정도는 차이 없었으며(ESS, 14.2 \pm 3.8 vs. $12.2 \pm 4.3, p=0.46)$, 수면다원검사에서도 유의한 지표는 없었다. 반면 이들의 MSLT 평균수면잠복기(1.2 \pm 0.6 분 VS. $4.6 \pm 3.4$ 분, $p=0.005)$ 와 렘수면잠복기가 유의하게 더 짧고 $(0.7 \pm 0.1$ 분 vs. $4.8 \pm 4.1$ 분, $p=0.01), \mathrm{SOREM}$ 의 횟수가 더 많
았다(4.3 \pm 1.1 회 vs. $3.8 \pm 1.0$ 회, $p=0.03)$. NT2 환자들 중 반복 검사에서 연속적으로 NT2에 합당한 결과가 확인된 환자는 15 명이었고 1 회 이상 NT2가 아닌 것으로 나온 환자는 27명 이었다. 주관적 졸림 정도 $(\mathrm{ESS}, 11.7 \pm 5.0$ vs. $12.9 \pm 5.0, p=$ 0.50) 및 수면다원검사의 지표는 차이가 없었으며, 짧은 MSLT 평균수면잠복기(5.4 \pm 4.1 분 Vs. $3.0 \pm 2.2$ 분, $p=0.02)$ 및 렘수 면잠복기(5.8 \pm 2.5 분 vs. $3.7 \pm 1.9$ 분, $p=0.01)$ 와 많은 $\mathrm{SOREM}$ 횟수(2.1 \pm 1.5 회 Vs. $3.6 \pm 1.0$ 회, $p=0.01)$ 가 반복검사에서 연 속적으로 NT2로 확인된 환자들의 특성이었다. 


\section{고 찰}

중추과다수면장애는 평생 지속되는 질환으로 알려져 있 고, 특히 히포크레틴 결핍과 연관성이 높은 NT1은 시간 경 과에 따른 임상 양상의 변화가 적은 만성질환으로 간주된 다. ${ }^{14}$ 하지만, 실제 임상현장에서는 10 20대에 NT1 또는 NT2 로 진단받았으나, 시간이 지남에 따라 주간졸음 정도가 감소 하여 약물을 복용하지 않고 지내는 환자들도 꽤 관찰하게 되 어, 임상정보와 MSLT(polysomnography 포함한)에 의거한 진단법의 한계를 실감하는 경우가 많다. NT1의 경우, 뇌척 수액안의 히포크레틴 농도가 비교적 정확한 바이오마커로 알려져 있으나 국내에서는 용이하지 않아서, 탈력발작 동반 여부와 MSLT의 $\geq 2 \mathrm{SOREM}$ 출현에 진단을 의존하게 된다. 하지만, 탈력발작의 빈도가 적고 경하거나 증상이 비전형적 인 경우 간과되기 쉽다. 반면, 심한 졸음증의 경우 수면발작 이 발생하면서 신체 근육강도가 약간 떨어지는 것을 탈력발 작으로 보고하기도 한다. 또한 탈력발작과 수면발작이 동시 에 발생하기도 하여, 증상으로 정확한 판단이 어려운 경우가 많다. MSLT에서 짧은 수면잠복기 및 심지어 $\geq 2$ SOREM을 야기할 수 있는 상황은, 기면병 외 심한 호흡장애, 만성적인 수면부족 또는 일주기리듬수면각성장애를 동반한 경우이 다. 충분한 전처치(예를 들어, 일주일 이상의 수면일기 작성 을 통해 수면부족과 수면위상변경을 확인하거나, 심한 호흡 장애의 경우 양압기를 착용한 상태에서 MSLT를 시행하거 나, 주간졸음을 초래할 수 있는 약물복용을 2주 이상 중단하 게 하는 등) 후 MSLT 반복검사를 하는 것이 기면병 진단의 남발을 막을 수 있는 가장 현실적인 방법이다.

히포크레틴-1의 결핍과 관련이 적은 NT2 또는 $\mathrm{IH}$ 는 평 균 4년 정도 경과를 관찰하면 50\%에서 MSLT 결과가 바뀔 뿐만 아니라, 임상적으로 치료하지 않아도 주간졸림이 호전 되는 경우도 많다고 보고된 바 있다. ${ }^{12}$ 문헌에 따라 좀 더 낮 은 MSLT 검사의 신뢰성을 보고했는데, 평균 1.9년 후 NT2 의 $53 \%$ 에서 진단이 변경되었고, 평균 2.9 년 후 NT2의 $82 \%$ 에서 진단이 변경되었다. ${ }^{10,11}$ 비교적 안정적인 경과로 알려져 있는 NT1도 두 번 검사에서 검사-재검사 신뢰도는 $72.7 \%$ 에 서 $78 \%$ 정도이다. ${ }^{10,11}$ 기존 연구들은 대부분 2 회의 검사 또는 짧은 경과 관찰 기간(2년 이내)에 근거하여 MSLT의 진단 신 뢰성을 평가했다.

반면 본 연구는 2회 이상의 MSLT 검사와 장기적 추적관 찰을 통해 기면병 환자의 MSLT 기반 진단 신뢰성을 평가했 다는 점에서 큰 의의가 있다. 첫 번째 검사에서 NT1과 NT2 로 진단한 각 38명과 42명에서 각각 4년, 3.7년 후 시행한 두 번째 검사 결과로 판단했을 때, NT1의 $24.1 \%(7$ 명), NT2의
$64.5 \% \%$ (20명)이 기면병이 아닌 것으로 나타났다. 이 중 세 번째 검사를 시행한 NT1의 9명 중 3명(33.3\%)만이 NT1로 진단되었으며, 11명의 NT2 중 4명(36.3\%)만 NT2로 동일하 게 나타났다. 기존 연구에 비해 확실히 낮은 수치이다.

또한 2회 이상의 MSLT에서 모두 NT1으로 진단된 환자 들의 MSLT 결과가 진단이 변경된 환자들보다 유의하게 더 짧은 평균수면잠복기(1.2분), 렘수면잠복기(0.7분), 더 많은 $\operatorname{SOREM}(4$ 회)를 보였다. 비록 기면병 진단 기준이 평균수면 잠복기 8분 이하와 $2 \mathrm{SOREM}$ 이상으로 정해져 있으나, NT1 의 경우 횔씬 나쁜 지표를 보였다. 따라서, 기준 경계치를 가 까스로 도달한 NT1 환자에서 탈력발작 여부가 불분명할 경 우, NT2 혹은 다른 중추성과다수면장애의 가능성을 염두에 두면서 추적관찰 및 검사를 하는게 낫겠다. 추가로, 이 환자 들의 ESS 지수(14점)가 다른 환자들(12점)과 비교하여 큰 차 이가 없었고 이는 주관적 ESS 보다는 객관적인 MSLT의 소 견이 더 정확하게 예후와 경과를 알려주는 지표라는 점을 시사한다.

NT2의 경우, 시간 경과에 따른 진단 변경율이 매우 높았는 데, 특히 첫 검사에서 NT2로 진단된 64.2\%의 환자에서 결국 진단이 변경되었으며(과수면병, 렘 조절 장애), 13명(30.9\%) 은 최종적으로 정상으로 판명되었다. 이 결과는 기면병 특히 NT2의 경과가 현재까지 알려진 바처럼 비슷한 임상적 강도 로 평생 진행하는 것이 맞는지에 대한 의구심을 불러 일으 킨다.

본 연구는 타 연구에 비해 경과 관찰 시기가 길고, 세 번째 까지 검사를 진행했다는 점에서 큰 의미를 갖는다. 두 번째 검사까지 기면병 진단 유지율은 NT1 75.9\%(22/29), NT2 $35.5 \%(11 / 31)$ 로 이전 연구와 유사하거나, 약간 낮은 정도이 다. 그러나, 세 번째 검사를 시행하면서 진단 유지율은 각각 $33.3 \%, 36.3 \%$ 로 큰 폭으로 감소했다. 5 년 이상 장기간의 경 과관찰에 의한 기면병의 특성에 대한 연구는 거의 없다. NT1 과 NT2의 MSLT 신뢰도는 연구에 따라 추적관찰 기간이 다 양하지만 대체로 2.7 년에서 6년의 기간동안 진행되었으며, 그 이상의 기간에서 NT1과 NT2의 신뢰도 특성을 분석한 경 우는 본 연구 뿐이다.

본 연구의 한계는 다음과 같다. 첫 번째, 후향적 의무기록 분석으로 모든 환자에서 같은 시기에 추적검사를 한 것이 아 니라서 검사 간격이 일정하지 않다. 두 번째, 국내 의료 현실 이기는 하지만 NT1의 진단에 히포크레틴 농도가 이용되지 못했다. 탈력발작은 매우 주관적인 증상이며, 늘 같은 강도 와 빈도로 발생하지 않고, 환자의 기억에 의존하는 제한이 있다. 또한 환자에 따라서 수면발작에 자주 빠지는 경우, 탈 력발작으로 오해하여 답변하는 경우도 있어서 NT1로 오진 
할 수 있다. 세 번째 2008년부터 2014년까지 본원에서 MSLT 를 처방할 때 전처치를 제대로 하지 못했다. 수면일기 또는 액티그래피를 적극적으로 활용하여 검사 전에 교육하고 시 행해야 하는데, 모든 환자에게 처방되거나 제대로 실행되지 못했다. 또한 반복검사를 하는 대부분의 환자들은 중추신경 자극제나 비정상적인 렘수면 양상(탈력발작, 환각, 악몽, 렘 수면행동장애 등)으로 인해 항우울제를 복용하고 있다. 검 사를 위해 2주 이상 약물을 중단하게 교육은 하나, 실제 그 기간 동안 약물을 완전히 끊고 온 환자의 숫자는 파악하기 어렵다. 약을 먹지 않으면 일상생활 유지가 힘든 환자들은 의료진에 보고하지 않고 약을 복용했을 가능성이 높아서(물 론, 검사당일에는 복용하지 않은 것을 확인했다) 약물영향을 완전히 배제하기 어렵고, 이 경우 MSLT는 SOREM이 출현 하지 않아 기면병이 아닌 것으로 분류되었을 가능성이 높다. 결론적으로, 지난 12 년간 본원에서 기면병으로 진단한 환 자들 중 NT1의 $34.2 \%, \mathrm{NT} 2$ 의 $64.2 \%$ 는 기면병이 아닌 것으 로 판정되었다. 대부분은 과수면증, 렘조절장애로 진단이 변 경되었으나, NT1의 5.2\%(2명)와 NT2의 23.8\%(10명)는 정 상으로 최종 판정되었다. 기면병은 국가의 희귀난치성질환 자 산정특례 대상으로 많은 의료비 혜택을 받는 질환이다. 최근 전처치 없는 MSLT의 남발로 국내 기면병 유병율이 증 가하고 이에 따른 의료비 지출도 늘어나는 실정이다. 만성수 면부족이 만연한 국내 현실을 반영한다고도 볼 수 있다. 하 지만, 질병의 정확한 진단과 치료는 의료인의 의무이며 책임 임을 되새겨야 할 것으로 보인다. 향후 정교한 연구계획을 세워 주기적 검사와 관찰을 통한 기면병의 경과에 대한 추가 연구가 필요할 것으로 보인다.

\section{Acknowledgments}

None.

\section{Conflicts of Interest}

The authors have no potential conflicts of interest to disclose.

\section{ORCID iDs}

Min Jae Seong Su Jung Choi Seung Bong Hong Eun Yeon Joo

\section{Author Contributions}

Conceptualization: Min Jae Seong, Eun Yeon Joo, Seung Bong Hong.
Data curation: Min Jae Seong, Su Jung Choi, Eun Yeon Joo. Formal analysis: Min Jae Seong, Eun Yeon Joo. Investigation: Min Jae Seong, Eun Yeon Joo. Methodology: Min Jae Seong, Eun Yeon Joo. Project administration: Min Jae Seong, Eun Yeon Joo. Resources: Eun Yeon Joo. Software: Eun Yeon Joo. Supervision: Eun Yeon Joo. Validation: Eun Yeon Joo. Visualization: Su Jung Choi, Eun Yeon Joo. Writing_-original draft: Min Jae Seong, Eun Yeon Joo. Writing_review \& editing: Min Jae Seong, Eun Yeon Joo, Seung Bong Hong.

\section{REFERENCES}

1. American Academy of Sleep Medicine. International classification of sleep disorders. 3rd ed. Darien: American Academy of Sleep Medicine, 2014.

2. Dauvilliers Y, Arnulf I, Mignot E. Narcolepsy with cataplexy. Lancet 2007;369:499-511. https://doi.org/10.1016/S0140-6736(07)60237-2.

3. Kim HW, Cho JW. Narcolepsy, how do we manage it? J Sleep Med 2020;17:1-10. https://doi.org/10.13078/jsm.200006.

4. Carskadon MA, Dement WC, Mitler MM, Roth T, Westbrook PR, Keenan S. Guidelines for the multiple sleep latency test (MSLT): a standard measure of sleepiness. Sleep 1986;9:519-524. https://doi.org/ 10.1093/sleep/9.4.519.

5. Bassetti C, Gugger M, Bischof M, et al. The narcoleptic borderland: a multimodal diagnostic approach including cerebrospinal fluid levels of hypocretin-1 (orexin A). Sleep Med 2003;4:7-12. https://doi.org/10.1016/ s1389-9457(02)00191-0.

6. Hong SC, Lin L, Jeong JH, et al. A study of the diagnostic utility of HLA typing, CSF hypocretin-1 measurements, and MSLT testing for the diagnosis of narcolepsy in 163 Korean patients with unexplained excessive daytime sleepiness. Sleep 2006;29:1429-1438. https://doi. org/10.1093/sleep/29.11.1429.

7. Mignot E, Lin L, Finn L, et al. Correlates of sleep-onset REM periods during the Multiple Sleep Latency Test in community adults. Brain 2006;129:1609-1623. https://doi.org/10.1093/brain/awl079.

8. Singh M, Drake CL, Roth T. The prevalence of multiple sleep-onset REM periods in a population-based sample. Sleep 2006;29:890-895. https://doi.org/10.1093/sleep/29.7.890.

9. Han SJ, Joo EY, Cho JW, Hong SB. The usefulness of repeated multiple sleep latency test for the diagnosis of narcolepsy. J Korean Sleep Res Soc 2008;5:39-42. https://doi.org/10.13078/jksrs.08006.

10. Ruoff C, Pizza F, Trotti LM, et al. The MSLT is repeatable in narcolepsy type 1 but not narcolepsy type 2: a retrospective patient study. J Clin Sleep Med 2018;14:65-74. https://doi.org/10.5664/jcsm.6882.

11. Lopez R, Doukkali A, Barateau L, et al. Test-retest reliability of the multiple sleep latency test in central disorders of hypersomnolence. Sleep 2017;40:zsx164. https://doi.org/10.1093/sleep/zsx164.

12. Trotti LM, Staab BA, Rye DB. Test-retest reliability of the multiple sleep latency test in narcolepsy without cataplexy and idiopathic hypersomnia. J Clin Sleep Med 2013;9:789-795. https://doi.org/10.5664/ jcsm.2922.

13. Berry RB, Brooks R, Gamaldo C, et al. AASM scoring manual updates for 2017 (version 2.4). J Clin Sleep Med 2017;13:665-666. https://doi. org/10.5664/jcsm. 6576 .

14. Dauvilliers Y, Siegel JM, Lopez R, Torontali ZA, Peever JH. Cataplexy-clinical aspects, pathophysiology and management strategy. Nat Rev Neurol 2014;10:386-395. https://doi.org/10.1038/nrneurol.2014.97. 